\title{
Market Capturing and Business Expansion Strategy for Gluten-Free Foods in India and USA Using PESTEL Model
}

\author{
Jolly Masih"1, Rajasekaran Rajkumar², Paviter Singh Matharu' ${ }^{3}$, Amita Sharma ${ }^{4}$ \\ ${ }^{1}$ Erasmus School of Economics, Erasmus University Rotterdam, Rotterdam, The Netherlands \\ ${ }^{2}$ School of Computer Science and Engineering, Vellore Institute of Technology, Vellore, India \\ ${ }^{3}$ Mosaic Company India Pvt. Ltd., Jalandhar, India \\ ${ }^{4}$ Institute of Agribusiness Management, Bikaner, India \\ Email: jolly.iabm@gmail.com, vitrajkumar@gmail.com,paviter.iabm@gmail.com, amita@iabmbikaner.org
}

How to cite this paper: Masih, J., Rajkumar, R., Matharu, P.S. and Sharma, A. (2019) Market Capturing and Business Expansion Strategy for Gluten-Free Foods in India and USA Using PESTEL Model. Agricultural Sciences, 10, 202-213.

https://doi.org/10.4236/as.2019.102017

Received: January 26, 2019

Accepted: February 24, 2019

Published: February 27, 2019

Copyright (c) 2019 by author(s) and Scientific Research Publishing Inc. This work is licensed under the Creative Commons Attribution International License (CC BY 4.0).

http://creativecommons.org/licenses/by/4.0/

\begin{abstract}
The ultimate goal for any business is to grow vertically and horizontally. Successful business is combination of careful analysis of external and internal factor of business environment and adoption of appropriate business strategy. In this study external factors of gluten-free market are studied in detail through PESTEL model (for external factors). The study would facilitate manufacturers to bring gluten-free foods from niche market to main stream market and to make it more affordable for all the sections of the society. The study focuses on markets of India and USA, since both of these nations have high potential for gluten-free foods and the demand further continues to increase every year.
\end{abstract}

\section{Keywords}

Gluten-Free, Wheat, Business Strategy, Celiac Disease, PESTEL Model

\section{Introduction}

India is an important global producer of important gluten-free sources such as sorghum (5.54 million MT), rice (106.54 million MT), corn, soybeans (9.8 million MT), millets (11.66 million MT), and pulses in MY 2013/14, according to the USDA. However, wheat has been a staple diet in the northern parts of India and this can lead to higher risks for celiac disease among the consumers. With the increasing rate of diagnosis and awareness about celiac disease, the demand for gluten-free products is projected to grow in terms of value at the highest 
CAGR of $10.7 \%$ from 2015 to 2020 in the Asia-Pacific region. The demand has also been increasing in other parts of India as consumers are seeking more processed varieties of gluten-free products [1].

North America is the largest market for gluten-free products which accounted for a market share of $52 \%$ in 2014. The celiac disease incidence rate for Americans is one in 133. About three million Americans have celiac disease and a further estimated 40 million suffer from gluten-intolerance or sensitivity. It has been anticipated that the number of celiac patients is expected to double every 15 years [2].

Gluten-free products were initially an important niche product segment but have now become part of the mainstream market. Gluten-free foods are available in almost all the food categories [3] (see Figure 1).

In 2014, bakery products accounted for the largest market share of $38.43 \%$, followed by cereals \& snacks contributing $21.88 \%$ in the gluten-free market, globally. Cereals \& snacks segment is projected to be the fastest growing market in terms of value at a CAGR of $10.9 \%$ from 2015 to 2020 [4]. The salty snack segment accounted for $65 \%$ of the market share in 2016. Manufacturers are using vegetables and legumes to create snacks that are not only gluten free but also offer health benefits such as increased fiber and nutrients. Incorporating ancient grains is another way manufacturers could use to create value added gluten-free snacks. These include grains like amaranth, buckwheat, chia, millet, sorghum and teff [5].

Companies have selected various distribution channels to reach consumers. These companies promote the product in the market with the help of multiple

GLUTEN-FREE PRODUCTS MARKET (2015 VS. 2020)

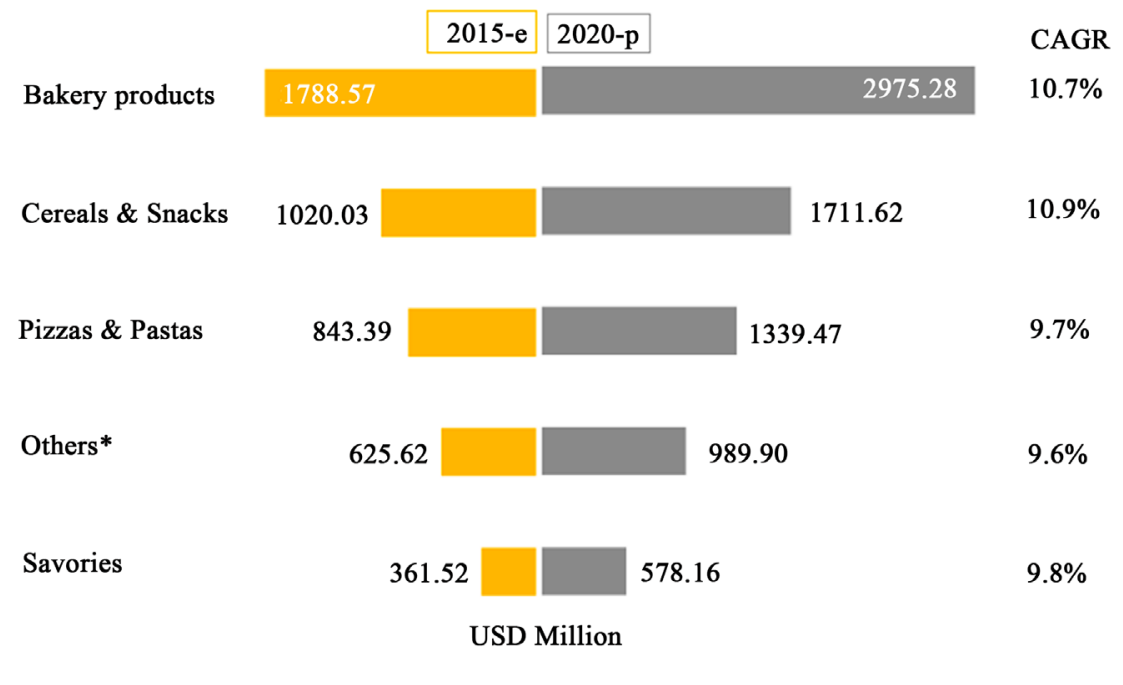

e-Estimated; p-Projected

*Others include dairy, meat, and confectionary products

Figure 1. Global market for gluten-free products for different food categories. Source: Markets and Market, 2015. 
strategies such as online retailing. Conventional stores have the potential to be a prominent distributional channel for gluten-free food products [6]. Niche retailers among these stores also realized the opportunity to establish an effective retail chain. Improving the quality and selection of gluten-free foods available in mainstream channels will help sales in the category grow nearly 1.5 times through 2019, according to market analysis by Packaged Facts, 2016. While the competition in the gluten-free market is heating up, the category remains highly fragmented, which means smaller companies still can gain a foothold against mega-brands [7].

Depending on the number of participants and the structure, there are several types of distribution channels. Mainly important channels are distribution channels of retailer, centralized distribution channels, decentralized distribution channels, distribution channels of manufacturers, direct channel of distribution with specialized logistics service provider. Common indicators of distribution system are warehouse costs, transportation costs, inventory costs, equipment costs, service levels, delivery time, degree of fault and the volume of business. There has been increase in sales with the help of certain channels such as educational institutions and hospitality sectors. Hospitality sectors include hospitals, airline services, and hotels which provide special attention to gluten-sensitive consumers and extend their offerings to non-celiac consumers as well [8].

In spite of high growth, gluten-free foods are facing problems to establish themselves in Asia market due to high price, lack of awareness about the products, increased number of un-diagnosed cases and inefficient value chain for gluten-free products. One of the major issues in India and USA is sky touching prices of gluten-free foods as compared to regular products. Going forward, the price of gluten-free foods will remain high until more people are diagnosed with celiac disease or prefer to purchase gluten-free foods for other reasons. In other words, the price will be high until critical mass in the retail and manufacturing segments is reached. House [9] reported that gluten-free foods were 242 per cent more expensive than comparable, regular products. In a new study by Sharma [10] found that difference has shrunk. Gluten-free flours, baked goods and prepared foods are now 162 per cent more than regular products. In this study a suitable strategy for business expansion and penetration was suggested with help of multi-stage analysis. Word cloud analysis was done for popular keywords related to gluten-free foods to provide a bird-eye view for consumer perception of gluten-free foods [11]. Then PESTEL model was carried to understand the external factors affecting gluten-free food industry in both the countries [12] [13].

\section{Discussion}

\subsection{Word Cloud for India \& USA}

Word cloud provides us a bird eye view about different keywords and perceptions been associated with any topic. It gives us an idea about most popular trends amongst any population. 
In Figure 2, word cloud provides a glimpse of most common keywords been associated with gluten-free food in India. Bigger size words indicate higher popularity of a particular keyword compared to other keywords. In India rice, celiac disease, Wheafree, Dr. Schar, gluten-free flour and chocolate cookies are most commonly used keywords, in context of gluten-free foods.

In Figure 3, word cloud of USA is densely populated, since it has many popular keywords associated with gluten-free foods. Most popular keywords are Udi's, bread, flour, celiac disease, veganism, autism, lactose-intolerance, biscuits, Pamela's, rice, quinoa, malnourished and local bakeries.

In order to set up a new business in any country, a detailed analysis of industry's external factors shall be done. It helps to under socio-cultural environment of the country and enables a firm to understand industry attractiveness.

\subsection{PESTEL Model Analysis for India and USA}

PESTEL model is used to study six major external factors namely political, economic, social, technological, environmental and legal factors associated with any industry in any particular area or country. It provides us an idea about overall external environment which might affect production and marketing activities for particular industry.

The PESTEL Model for gluten-free industry in India was created to understand the external factors affecting gluten-free foods in India (see Figure 4).

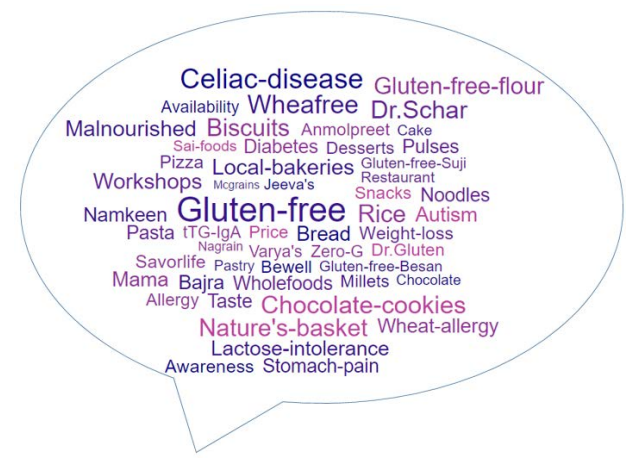

Figure 2. Word cloud for gluten-free foods in India.

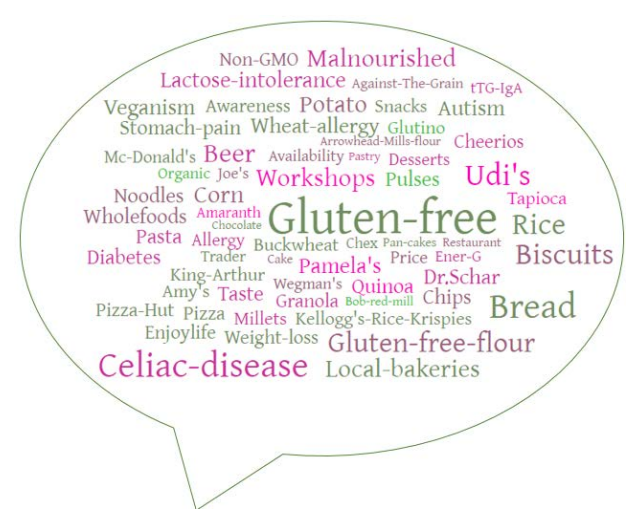

Figure 3. Word cloud for gluten-free foods in USA. 


\begin{tabular}{|c|c|c|}
\hline 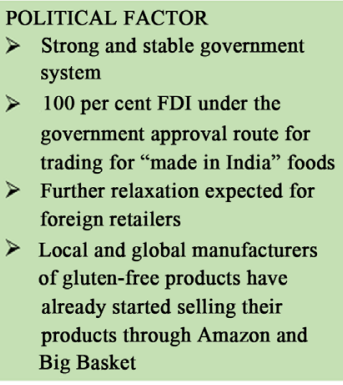 & $\begin{aligned} & \text { ECONOMIC FACTOR } \\
&>\text { Estimated inflation rate in } 2017 \\
& \text { is } 2.24 \% \\
&>\quad \text { Rise in purchasing power parity } \\
&>\quad \& \text { disposable income } \\
&>\text { After } 100 \% \text { FDI in food, potential } \\
& \text { investments could be } \$ 5-10 \text { billion } \\
&>\text { Between April and December of } \\
& \\
& 2016-17 \text {. the FDi in flow rose } \\
& \text { \$46.40 billion, up } 1 \% \text { from } 2015-16 \\
&>\quad \text { launching the product in smaller } \\
& \text { packs can help the company fight } \\
& \text { price competition and inflation }\end{aligned}$ & $\begin{array}{l}\text { SOCIAL FACTOR } \\
70 \% \text { population is rural and farming } \\
\text { community } \\
>\quad \text { Gluten-free foods made up of ancient } \\
\text { grains and herbs could be beneficial } \\
\text { Indians consumers are price sensitive } \\
\text { and seek value for money } \\
>\text { Indians are fond of spicy foods, thus } \\
\text { salty snacks and savouries containing } \\
\text { red chilli, black pepper, mint and other } \\
\text { herbs to make it suitable for Indian } \\
\text { taste buds }\end{array}$ \\
\hline 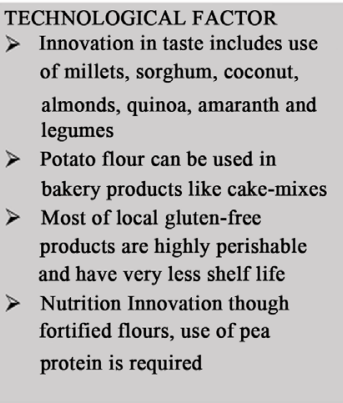 & 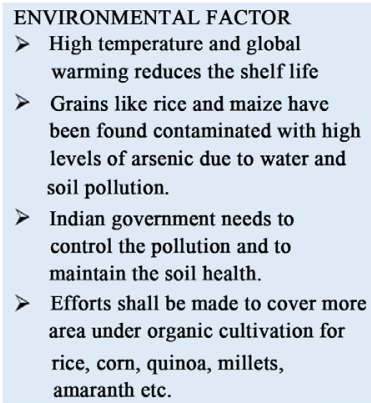 & $\begin{array}{l}\text { LEGAL FACTOR } \\
>\text { Rules are monitored by FSSAI } \\
>\text { Rules for imported companies- } \\
\text { Licensing of food importer, } \\
\text { clearance of imported food, } \\
\text { Storage, sampling and inspection, } \\
\text { addressing of queries } \\
>\text { Rules for Indian companies-Gluten- } \\
\text { free foods shall contain gluten } \\
\text { content less than } 20-100 \mathrm{mg} / \mathrm{kg}\end{array}$ \\
\hline
\end{tabular}

Figure 4. PESTEL Model for gluten-free food industry in India.

\subsubsection{Political Factor}

Currently India has strong and stable government system. Modi government is taking lots of measures to improve food security and to bring food reforms in specialty foods. The government has permitted 100 per cent FDI under the government approval route for trading, including through ecommerce, of food products "made in India" [14]. Recently, e-commerce players Amazon, Big Basket and Grofers applied for approval for retailing locally-produced food products, promising a combined investment of $\$ 695$ million. The government is further relaxing foreign direct investment (FDI) rules in the retailing of food products, to make it even easier for top foreign retailers to invest in India [15].

Local and global manufacturers of gluten-free products have already started selling their products through Amazon and Big Basket.

\subsubsection{Economic Factor}

Estimated inflation rate in $2017-18$ is $2.24 \%$ [16]. After $100 \%$ FDI in food, potential investments could be as much as $\$ 5-10$ billion. Between April and December of 2016-17, the FDI inflows rose $\$ 46.40$ billion, up 1\% from 2015-16 ( $\$ 40$ billion). Indians consumers are price sensitive and seek value for money. Therefore, launching the product in smaller packs can help the company fight price competition and inflation.

\subsubsection{Social Factor}

Rural society and farming community dominates the Indian society. The decision to allow $100 \%$ FDI in marketing of locally-produced food items was important as food and farm items worth INR 92,651 crore gets wasted annually in India due to a low level of processing and inadequate infrastructure for scientific storage. India is the world's largest producer of milk and the second-largest 
grower of rice, wheat, fruit and vegetable, but the processing level is just 10\% [17]. Most of population is vegetarian in India thus launching gluten-free foods made up of ancient grains and herbs could be beneficial. Indians are fond of spicy foods, thus salty snacks and savouries shall contains herbs like red chilli, black pepper, mint and other herbs to make it suitable for Indian taste buds.

\subsubsection{Technological Factor}

Technology can reduce costs, improve quality and lead to innovation. Innovative manufacturing technologies and development of flours, starches and bran made from alternative ingredients, helps in enhancing both taste and appearance. Innovation in taste includes use of millets, sorghum, coconut, almonds, quinoa, amaranth and legumes. Potato flour has gained acceptance in bakery products like cake-mixes and cookies [18].

On index of air, water and noise pollution, India is one of the most populated and polluted country. High temperature and global warming effect in India reduces the shelf life of products. At many places grains like rice and maize

Technological innovations are also required in packaging of gluten-free products to improve their shelf life. Most of local gluten-free products are highly perishable and have very less shelf life compared to imported brands. Nutrition Innovation though fortified flours, use of pea protein can be helpful in increasing the consumer base.

\subsubsection{Environmental Factor}

Raw material for glute-free products have been found contaminated with high levels of arsenic due to water and soil pollution. Thus Indian government needs to work very hard to control the pollution and to maintain the soil health. Good environment can only produce healthy food. Sikkim is only organic state of India. Since the demand for organic gluten-free foods is highest in market, thus efforts shall be made to cover more area under organic cultivation for rice, corn, quinoa, millets, amaranth etc.

\subsubsection{Legal Factor}

Indian government has set up many rules and regulations under FSSAI for import and manufacturing of gluten-free food to ensure the quality of products and safety of consumers.

\subsection{Rules for Imported Companies}

With an increase the number of food imports into India the FSSAI, with a view to providing safe and wholesome food to Indian consumers has notified the Food Import Regulation 2017 as of 9 March 2017. These regulations lay down the provisions for:

- Licensing of food importer

- Clearance of imported food by the FSSAI

- Food import clearance for specific purposes

- Storage, sampling and inspection of imported food 
- Restriction on food imports

- Amenable food labelling provisions for ease of trade

- Easy addressing of queries related to clearance of food imports

Besides these the FSSAI has also made provisions for risk based sampling of imported foods as this facilitates ease of doing business without comprising on health of consumers [19].

\subsection{Rules for Indian Companies}

Through a notification dated 3 May 2016 the FSSAI has made further regulations to amend the Food Safety and Standards (Food Products Standards and Food Additives) Regulations, 2011 relating to standards for gluten food and low gluten food. The FSSAI has pointed out that any food, which by its nature, is suitable for use as part of a gluten free diet cannot be named "special dietary", "special dietetic" or any other equivalent term. Such food can carry a statement on the label which says that "this food is by its nature gluten-free".

The label declaration will be as per provision of the Food Safety and Standards (Packaging and Labelling) Regulations, 2011 [19].

A product can be labelled as gluten free only after the product has been analysed and found to be below $20 \mathrm{mg} / \mathrm{kg}$ as per the method declared by the Organization for Economic Co-operation and Development or the Association of Official Agricultural Chemists.

Another regulation which is proposed to be added is "Food specially processed to reduce gluten content to a level $20-100 \mathrm{mg} / \mathrm{kg}$." This food has been defined as food that consists of one or more ingredients which may contain rice, millets, ragi, oats, rye, barley, maize, wheat, pulses and legumes containing gluten content in the range of $20-100 \mathrm{mg} / \mathrm{kg}$. It shall bear the label declaration referred to in the Food Safety and Standards (Packaging and Labelling) Regulations, 2011 [19].

For foods that are termed Gluten Free Foods the labelling requirements is to print the words "Gluten Free" in the immediate proximity of the name of all such products. The term "Low Gluten" shall be printed in the immediate proximity of the name of the product in the case of products termed Foods specially processed to reduce gluten content to a level $20-100 \mathrm{mg} / \mathrm{kg}$. This label shall also carry a "warning" that "the food labelled as Low Gluten may pose a risk for those with celiac disease" [19].

Next, The PESTEL Model for gluten-free industry in USA was created to understand the highly competitive market of gluten-free foods in USA (see Figure 5).

\subsubsection{Political Factor}

Trump government has liberalized the Food and Drug Administration's regulations on food safety, labelling and trade. A new law has been passed to require labelling for genetically-modified organisms in food. Budget cuts would be there for the Food and Drug Administration and the Food Safety and Inspection Service of the Department of Agriculture. It would lead to less enforcement of 


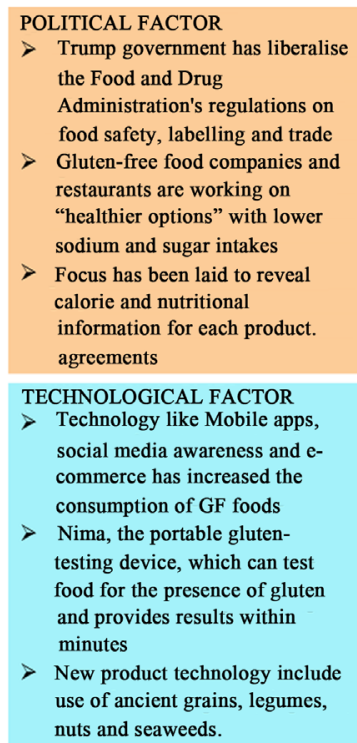

ECONOMIC FACTOR

USA has economic stability and gradually rising employment rate

The rising labour costs in developing countries can lead to higher supply costs and higher selling prices Expected inflation rate in 2017 is $2.54 \%$

$>$ USA economy is in bull market (stock are rising), thus attractive packaging, honest claims like vegan, sugar-free, non-GMO, increased product availability through ecommerce can help to increase consumer base

ENVIRONMENTAL FACTOR

$>$ Government shall take proper measures to deal with global warming and climate change

$>$ More complex standards on business waste disposal
SOCIAL FACTOR

$>$ Young generation is highly driven towards healthy food trends

Gluten-free products with claims like organic, sugar-free, vegan and non-GMO are popular

$>$ High demand for fresh and authentic flavour built in American style.

$>$ Strong value proposition for quick and convenient food, thus creating an opportunity for gluten-free flours and mixes

LEGAL FACTOR

$>$ Foods shall contain gluten content less than $20 \mathrm{ppm}$

$>$ "gluten-free" claim can appear on the labels of foods that inherently do not contain gluten (e.g. raw carrots and grapefruit juice)

$>$ Hydrolysed, fermented, or distilled foods voluntarily bearing the "gluten-free" claim will also have to meet the requirements of the gluten-free food labelling rule

Figure 5. PESTEL Model for gluten-free food industry in USA.

food contamination, fewer reviews of food advertising, food labelling and less scrutiny of food additives. FDA is taking initiatives to reduce sodium in food. New rules for nutrition and labelling are in progress. It would affect exports of food and agricultural products. According to the USDA, agricultural exports were worth $\$ 133$ billion in 2015. In the same year, World Bank statistics showed food products made up about $10 \%$ of total U.S. exports. Gluten-free food companies and restaurants are working on "healthier options" as public health policies are pushing for foods with lower sodium and sugar intakes. Focus has been laid to reveal calorie and nutritional information for each product. American manufacturers have the opportunity to expand their business overseas based on advantages of free trade agreements.

\subsubsection{Economic Factor}

Gluten-free food manufacturers have the opportunity to grow based on the economic stability and gradually rising employment rate in the U.S.A. However, the rising labour cost in developing countries is a threat because the company's raw material significantly depends on grain and legume production in developing countries. The rising labour costs lead to higher supply costs and higher selling prices. Inflation rate of USA is increasing year on year. In 2016 it was $1.26 \%$ and in 2017 it is expected to be $2.54 \%$. According to the Federal Reserve (central bank of USA), ideal economy shall have inflation rate of 2-3\%. It allows consumers to spend on health and other recreational activities. Low inflation rates bind consumers and they are not able to make purchases beyond basic necessities [20]. Thus this is good time to launch new products by gluten-free manufacturing companies or to launch new product variants with better ingredients. Increasing purchasing power in USA will help in better positing and targeting of product. USA economy is in bull market (stock are rising), thus gluten-free 
manufacturing firms shall try shall to make their place through attractive packaging, honest claims like vegan, sugar-free, non-GMO etc. Product availability can be increased through ecommerce [21].

\subsubsection{Social Factor}

A report from American Census Bureau revealed that Millennials (ages 18 - 34 in 2015) forms largest portion of US population with a number of 75.4 million, followed by Baby Boomers (ages 51 - 69) with population of 74.9 million. And Generation X (ages 35 - 50 in 2015) is projected to pass the Boomers in population by 2028 [22]. According to the report living alone and having a job are most important life preferences for millennials [23]. Increase in number of working class women and young Americans living away from home create a platform for processed food industry.

Millennials are highly driven towards healthy food trends, thus there is wide scope for processed gluten-free products. Gluten-free products with claims like organic, sugar-free, vegan and non-GMO are expected to attract high number of millennials. Millennials are one of the driving forces behind the demand for fresh and authentic flavour built in American style. E.g. gluten-free Vietnamese noodle soup rich in herbs (authentic Vietnamese favour) but less in salt content (American style). Millennials seek strong value proposition for quick and convenient food, thus creating an opportunity for gluten-free flours and mixes [24].

\subsubsection{Technical Factor}

With an increase in social media platforms, consumer's interaction and attitude towards food is becoming more noticeable and important. With new digital and social media platforms, food is being embraced as a vehicle for self-expression and storytelling. For e.g. Instagram accounts "@you did not eat that" and "@food in the air" give an insight about the new ways in which people are consuming gluten-free foods [25].

Technological and product innovations lead to improved health, wellness and safety. Increasing automation has made home delivery of products through ecommerce easier. Preparing large batch sizes and providing attractive packaging has been the power of American food manufacturing firms. Mobile technology has provided facilities like scanning the barcode and getting information about ingredients and nutrients. Mobile apps help in finding nearby store providing gluten-free food. Mobile apps on health and fitness also help to maintain a healthy diet schedule [23].

Another technological milestone is achieved by introduction of Nima, the portable gluten-testing device, which can test food for the presence of gluten and provides results within minutes [26]. Many technological and product innovations are taking place to improve the taste and nutrients in gluten-free foods through use of ancient grains, legumes and seaweeds.

\subsubsection{Environmental Factor}

Global warming/climate change reduces the self-life of food products. Thus 
government shall take proper measures to deal with global warming and climate change issue for property of nation.

More complex standards on business waste disposal and higher emphasis on business sustainability shall be provided for subsistence of gluten-free products market.

At macro level, clean and pure environment also adds to increased sales of gluten-free foods. People like to dine out at a place which provides peaceful environment, free from pollution and life-hustle. They love the fresh ingredients been used in preparing the dishes. Thus a countryside or roof top gluten-free restaurant or beach-side gluten-free restaurant with a small kitchen garden or farm associated nearby can be a great idea to attract high number of consumers.

\subsubsection{Legal Factor}

According to FDA, the labelling claim that a food is "gluten-free" means that the food bearing the claim in its labelling does not contain any of the following ingredients:

- An ingredient that is a gluten-containing grain

- An ingredient that is made from a gluten-containing grain and that has not been processed to remove gluten. For example, "wheat flour" is an ingredient made from wheat that has not been processed to remove the naturally occurring gluten in wheat. Therefore, wheat flour cannot be used as an ingredient to make a food labelled "gluten-free"

- An ingredient that is made from a gluten-containing grain and that has been processed to remove gluten, if the use of that ingredient contains 20 parts per million (ppm) or more gluten. For example, wheat starch is an ingredient made from wheat that has been processed to remove gluten. However, the use of this ingredient must result in under 20 parts per million gluten in the finished food for the food to be labelled "gluten-free."

A "gluten-free" claim also can appear on the labels of foods that inherently do not contain gluten (e.g. raw carrots and grapefruit juice). Hydrolysed, fermented, or distilled foods voluntarily bearing the "gluten-free" claim will also still have to meet the requirements of the gluten-free food labelling final rule, including the definition of "gluten-free" [27].

The knowledge of external factors of the industry, would also help in the understanding of internal forces of industry.

\section{Conclusion}

By using the PESTEL model, the study has provided a pathway to manufacturers of gluten-free foods to enter in the challenging markets of India and USA. The strategy was formulated keeping in mind various socio-cultural and political factors in both the countries. It would facilitate manufacturers to bring gluten-free foods from niche market to main stream market and to make it more affordable for the masses. 


\section{Conflicts of Interest}

The authors declare no conflicts of interest regarding the publication of this paper.

\section{References}

[1] Masih, J. (2016) Value-Chain Analysis of Gluten-Free Foods. International Journal of Agricultural Science and Research, 6, 339-346.

[2] Cristina, P. (2016) Pure Oats as Part of the Canadian Gluten-Free Diet in Celiac Disease: The Need to Revisit the Issue. Canadian Journal of Gastroenterology and Hepatolgy, 16, 60.

[3] Collins (2011) Motivating and Enabling Value Chain Innovation. Value Chain Management Centre, 1, 2-8.

[4] Anonymous (2015) Gluten-Free Products Market by Type. Markets and Markets. http://www.marketsandmarkets.com/Market-Reports/gluten-free-products-market738.htm

[5] Crawford, E. (2015) Sales of Gluten-Free Products Continue to Grow Double Digits on Quality, Selection. Foodnavigator-usa.com.

http://www.foodnavigator-usa.com/Markets/Sales-of-gluten-free-products-will-con tinue-to-grow-double-digits

[6] Anonymous (2014) Free-From Foods. Mintel Global New Products Database. https://store.mintel.com/gluten-free-foods-us-september-2014

[7] Anonymous (2016) Gluten-Free Foods and Beverages Become Mainstream Sensations as Part of a Healthy Lifestyle Choice. Packaged Facts. http://www.packagedfacts.com/about/release.asp?id=1864

[8] Fernie (2009) Retail Logistics in the UK: Past, Present and Future. UK bits. http://storre.stir.ac.uk/bitstream/1893/2867/1/Fernie\%20et\%20al\%20probably\%20fi nal\%20version.pdf

[9] House, L. (2016) Is Gluten-Free the Most Expensive Fad Yet? Average Family Can't Afford to Follow the Diet with Everyday Staples Like Bread and Flour Costing up to 500 PERCENT More. Dailymail.co.uk, 1, 11.

[10] Sharma (2015) The Big Specialty Food Consumption Opportunity. India Retailing-Food Grocer, 6, 1-2.

[11] Anonymous (2017) What's a Word Cloud? Worditout. https://worditout.com/

[12] Anonymous (2017) PESTLE-Macro Environmental Analysis. Oxlearn. https://www.oxfordlearninglab.com/p/pestle-macro-environmental-analysis

[13] Bivolaru, E., Andrei, R. and Purcaroiu, G.V. (2009) Branding Romania: A PESTEL Framework Based on a Comparative Analysis of Two Country Brand Indexes. Management \& Marketing, 4, No. 4.

[14] Anonymous (2016) Government Allows 100\% FDI in Trading of Food Products. The Economic Times. http://economictimes.indiatimes.com/

[15] Pattanayak, B. (2017) Reforms in Food Retail: Narendra Modi Government Mulls easy FDI Rules; Kitchenware, Beauty Products on Table. Financial Express. http://www.financialexpress.com/economy/reforms-in-food-retail-narendra-modigovernment-mulls-easy-fdi-rules-kitchenware-beauty-products-on-table/616931/

[16] Anonymous (2017) Historic Inflation India-CPI Inflation. Inflation.eu. http://www.inflation.eu/inflation-rates/india/historic-inflation/cpi-inflation-india.as px 
[17] Ambwani, V. (2016) FDI in Food Retail Will Draw Global Giants. Thehindubusinessline.

http://www.thehindubusinessline.com/economy/fdi-in-food-retail-will-draw-global -giants/article8300884.ece

[18] Sharma, M. (2017) Gluten-Free Products-Go for It! Food Marketing \& Technology. http://fmtmagazine.in/gluten-free-products-go/

[19] Anonymous (2017) FSSAI Proposes Standards Related to Gluten Free and Low Gluten Foods and Their Labelling Requirements. Foodsafetyhelpline.com.

https://en.wikipedia.org/wiki/Chandhttp://foodsafetyhelpline.com/2016/05/fssai-prop oses-standards-related-gluten-free-low-gluten-foods-labelling-requirements/igarh

[20] Anonymous (2017) Top Banking Trends to Watch in 2017. Plainscommerce.com. https://plainscommerce.com/news/top-banking-trends-to-watch-in-2017/

[21] Kathy, A. and Schwab, C. (2017) The Dollar Bull Market Will Stay Intact in 2017. Business Insider.

http://www.businessinsider.com/will-the-us-dollar-bull-market-continue-in-2017-2 017-1?IR=T

[22] Fry, R. (2016) Millennials Overtake Baby Boomers as America's Largest Generation. Pew Research Center.

http://www.pewresearch.org/fact-tank/2016/04/25/millennials-overtake-baby-boom ers/

[23] Nicastro, S. and Wallet, N. (2017) 3 Smart Business Ideas for Millennials in 2017. USA Today.

https://www.usatoday.com/story/money/business/smallbusiness/2017/05/11/3-smar t-business-ideas-millennials-2017/101484624/

[24] Anonymous (2017) Build the Foundation of Your Menu. Gordon Food Service. https://www.gfs.com/en/products/product-categories/grocery

[25] Anonymous (2017) Millennials: The Foodie Generation. Corporate.univision.com. http://corporate.univision.com/blog/2014/12/15/millennials-the-foodie-generation/

[26] Anonymous (2016) Pocket-Sized Nima Sensor Tests Your Food for Gluten. Glutenfreeliving.

https://www.glutenfreeliving.com/gluten-free-foods/diet/sponsored-advertisementpocket-sized-nima-sensor-tests-food-gluten/

[27] Anonymous (2014) Gluten and Food Labeling. FDA.gov. https://www.fda.gov/Food/GuidanceRegulation/GuidanceDocumentsRegulatoryInf ormation/Allergens/ucm367654.htm/ 